\title{
Postgraduate medical education under microscope
}

Published at www.cmaj.ca on Mar. 17

$\mathrm{T}$ he Association of Faculties of Medicine of Canada is embarking on the second leg of a three-part journey to strengthen the country's medical education, armed with almost \$1.6 million in Health Canada funding to evaluate the postgraduate system.

The move follows the Jan. 28 release of a report detailing a vision for undergraduate medical education in Canada (CMAJ 2009. DOI:10.1503/cmaj.1093174). The third part of the evaluation plan will be the state of continuing education for physicians.

"When the project was conceived, we wanted to look at the continuum of the education for a physician in Canada," says Dr. Nick Busing, president and chief executive officer of the association.

For the postgraduate evaluation, the association is partnering with the College of Family Physicians of Canada, le Collège des médecins du Québec and the Royal College of Physicians and Surgeons of Canada. Health Canada announced Mar. 2 that it will provide roughly $\$ 1.6$ million over three years for the project under the Pan-Canadian Health Resources Strategy.

"Health Canada is confident that this collaborative project will foster innovative approaches to postgraduate medical education and help faculties of medicine prepare physicians with the skills needed to meet the evolving needs of Canada's health care systems," Philippe Laroche, a Health Canada media relations officer, wrote in an email.

According to Busing, the transition from medical student to resident will be looked at carefully to determine if students are properly prepared. Another area that needs examination is the amount of general medical knowledge physicians should possess.

"There is debate about what generalist competencies all physicians need," says Busing. "How much generalist

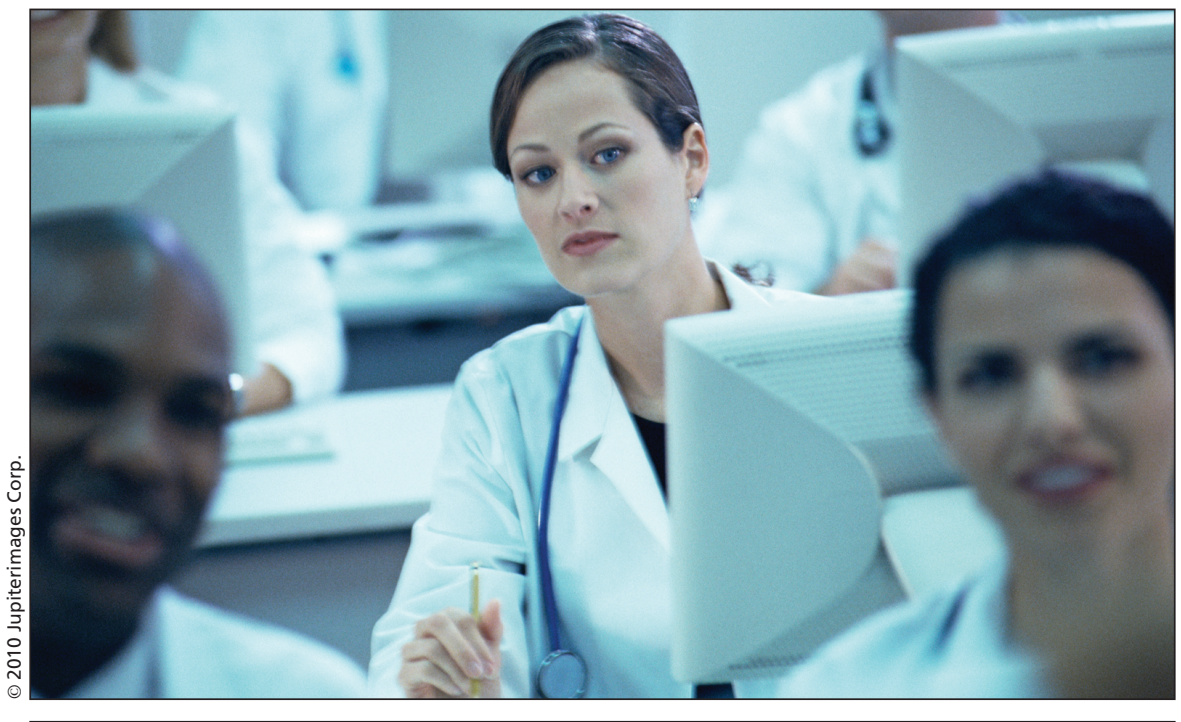

The Association of Faculties of Medicine of Canada is examining the continuum of medical education for Canadian physicians, from undergraduate to postgraduate to continuing education.

education does a vascular surgeon need compared to a family doctor?"

The issue of how many hours residents should work each week will also be explored. This topic has generated much debate: too few hours may dilute the clinical experience of residents, but too many hours may result in fatigue and put patients at risk. (CMAJ 2009. DOI:10.1503/cmaj.090772.)

Another focus will be on how to create a balanced workforce of generalists, specialists and subspecialists. There is also a need, Busing says, to ensure Canada is producing enough clinician educators, medical academics and clinician scientists.

"That's a challenge," says Busing. "The clinician scientist group is one we really need to bolster."

Some of the other areas to be considered in the postgraduate project - such as social accountability of physicians, incorporation of technology into education and training of doctors to work as part of interprofessional teams - parallel those examined in the undergraduate system, as outlined in the report, The Future of Medical Education in Canada (FMEC): A Collective Vision for MD
Education (www.afmc.ca/fmec/pdf/col lective_vision.pdf).

Although examining postgraduate medical education is important, the project should also attempt to anticipate the educational needs of physicians in the decades ahead, says Dr. Sal Spadafora, vice-dean of postgraduate medical education at the University of Toronto in Ontario.

"What kinds of physicians - specialists, generalists, primary care - are we going to need in the year 2030?" Spadafora asks.

The next generation of doctors will also be more tech-savvy, Spadafora notes, and may favour very different teaching methods than those currently used in medical schools, such as lectures via podcasts or increased use of surgical simulators.

Many of the approaches to educating physicians have been nearly the same for 20 years, says Spadafora, but that will likely have to change. "We will have to adapt to the style of learning of future physicians, whether we like it or not." - Roger Collier, CMAJ

DOI:10.1503/cmaj.109-3211 